\title{
The Polyphenol Oleuropein Aglycone Modulates the PARP1-SIRT1 Interplay: An In Vitro and In Vivo Study
}

\author{
Ilaria Luccarini ${ }^{\mathrm{a}, 1}$, Daniela Pantano ${ }^{\mathrm{a}, 1}$, Pamela Nardiello ${ }^{\mathrm{b}, 1}$, Leonardo Cavone $^{\mathrm{c}}$, Andrea Lapucci $^{\mathrm{d}}$, \\ Caterina Miceli $^{\mathrm{b}}$, Chiara Nediani ${ }^{\mathrm{b}}$, Andrea Berti ${ }^{\mathrm{b}}$, Massimo Stefani ${ }^{\mathrm{b}}$ and Fiorella Casamenti ${ }^{\mathrm{a}, *}$ \\ ${ }^{a}$ Department of Neuroscience, Psychology, Drug Research and Child Health, Division of Pharmacology \\ and Toxicology, University of Florence, Florence, Italy \\ ${ }^{\mathrm{b}}$ Department of Experimental Biomedical and Clinical Sciences, University of Florence, Florence, Italy \\ ${ }^{\mathrm{c}}$ Department of Health Sciences, University of Florence, Florence, Italy \\ ${ }^{\mathrm{d}}$ Department of Experimental and Clinical Medicine, University of Florence, Florence, Italy
}

Handling Associate Editor: Tommaso Cassano

Accepted 14 June 2016

\begin{abstract}
Poly(ADP-ribose) polymerase-1 (PARP1) activation contributes to the cascade of events initiated by amyloid- $\beta$ $(A \beta)$ peptide eventually leading to cell death in Alzheimer's disease brain. A significant accumulation of PAR polymers and increase of PARP1 expression were detected in the cortex at the early (3.5 months) and intermediate (6 months) stage of $\mathrm{A} \beta$ deposition in the TgCRND8 mouse model. Our previous data highlighted the beneficial effects of oleuropein aglycone (OLE), the main polyphenol found in the olive oil, against neurodegeneration both in cultured cells and in model organisms. Here we found that 8-week OLE treatment $(50 \mathrm{mg} / \mathrm{kg}$ of diet) to 6-month-old TgCRND8 mice rescued to control values PARP1 activation and the levels of its product, PAR. In N2a neuroblastoma cells, PARP1 activation and PAR formation upon exposure to N-methyl-N'-nitro-N-nitrosoguanidine (MNNG) were abolished by pretreatment for $24 \mathrm{~h}$ with either OLE $(100 \mu \mathrm{M})$ or PARP inhibitors. A significant reduction of the NAD ${ }^{+}$content, compared to controls, was found in N2a cells exposed to MNNG $(100 \mu \mathrm{M})$ for $90 \mathrm{~min}$; the latter was slightly attenuated by cell treatment for $24 \mathrm{~h}$ with PJ-34 or with OLE. In vitro and in vivo, the OLE-induced reduction of PARP1 activation was paralleled by the overexpression of Sirtuin1 (SIRT1), and, in vivo, by a decrease of NF- $\mathrm{KB}$ and the pro-apoptotic marker $\mathrm{p} 53$. In N2a cells, we also found that OLE potentiates the MNNG-induced increase of Beclin1 levels. In conclusion, our data show that OLE treatment counteracts neuronal damage through modulation of the PARP1-SIRT1 interplay.
\end{abstract}

Keywords: Alzheimer's disease, animal model of A $\beta$ deposition, olive oil polyphenols, PAR polymers

\footnotetext{
${ }^{1}$ These authors contributed equally to this work.

*Correspondence to: Fiorella Casamenti, Department of Neuroscience, Psychology, Drug Research and Child Health, Division of Pharmacology and Toxicology, University of Florence, Florence, Italy. Tel.: +39 055 2758286; E-mail: fiorella.casamenti@ unifi.it.
}

\section{INTRODUCTION}

Alzheimer's disease (AD) is the most common form of dementia presently affecting, in the developed countries, an estimated 44 million aged people that are expected to triple by 2050 . The key histopathological sign of $\mathrm{AD}$ is the diffuse presence of intracellular tangles of aggregated hyperphosphorylated tau and of minute extracellular amyloid- $\beta$ 
(A $\beta$ ) deposits found in senile plaques, around cerebral vessels, and close to dystrophic/degenerating neurites. According to the amyloid cascade hypothesis, plaque deposits are considered responsible for the functional alterations and behavioral deficits that characterize $\mathrm{AD}$ [1]. In the last 20 years, the interest in deciphering the relationship between plaque burden and neuronal death has increasingly focused on the importance of the oligomeric pre-fibrillar assemblies originating at the onset of fibril growth, as the main neurotoxic species [2].

In spite of its severity and the number of affected people, AD is a disease still in search of an effective therapy. Recent research has highlighted the potential therapeutic value against sporadic $\mathrm{AD}$ and other age-associated neurodegenerative diseases of several plant polyphenols, including resveratrol, quercetin, curcumin, oleuropein, oleocanthal, and hydroxythyrosol. The latter three compounds are found in the leaves and drupes of plants of the Oleaceae family, notably the olive tree and its main product, olive oil. Our previous data on neuroprotection by oleuropein aglycone (OLE) in TgCRND8 mice, a model of $A \beta$ deposition, showed a significant reduction of $A \beta$ levels, plaque load, and neuroinflammation together with a remarkable increase of the autophagic response in OLE-supplemented mice with respect to normally-fed littermates. These modifications matched a very significant improvement in cognition and memory in OLE-supplemented mice $[3,4]$ and suggested modifications of the expression levels of proteins involved in such processes, possibly with epigenetic implications. Accumulating evidence indicates that epigenetic deregulation of finely tuned processes involved in gene expression (such as DNA methylation, histone methylation, acetylation, and phosphorylation) might be crucial both in age-related memory impairment and in the pathogenesis of neurodegenerative diseases [5]. Interestingly, abnormal acetylation of histones is involved in learning and memory and might be causally associated to $\mathrm{AD}$ pathogenesis [6], also considering that histone acetylation seems to ameliorate cognitive deficits in $\mathrm{AD}$ animal models [7]. In line with this observations, we found in the cortex and hippocampus of our TgCRND8 mice an increased expression of the nuclear enzyme histone deacetylase 2 (HDAC2) and a subsequent reduction in histone 3 and 4 acetylation, in agreement with data previously reported in rats [7] and in AD patients [6]. Importantly, we observed that these modifications were fully reverted in OLE-supplemented Tg mice [4]. These data agree with previous data indicating that polyphenols such as resveratrol, quercetin, and catechins are able to activate sirtuin 1 (SIRT1), a class III HDAC involved in the pathogenesis of different chronic pathologies, including neurodegenerative diseases [8].

SIRT1 activity requires $\mathrm{NAD}^{+}$, and the activation of enzymes involved in the synthesis or consumption of $\mathrm{NAD}^{+}$plays an important role in the regulation of SIRT1 activity $[9,10]$. In addition to SIRT1, many other enzymes require $\mathrm{NAD}^{+}$as a substrate and, among these, poly (ADP-ribose) polymerase1 (PARP1) plays a role in many processes related to neurodegeneration [11]. The normal function of PARP1 is the routine repair of DNA damage by adding poly (ADP ribose) polymers in response to a variety of cellular stresses by its ability to convert $\mathrm{NAD}^{+}$in chains of poly(ADP-ribose) (PAR) polymers. Many additional functions of PARP1 have now been demonstrated in biochemical and molecular signaling [12]. In the CNS, PARP inhibition attenuates injury in pathologies like cerebral ischemia, trauma, and excitotoxicity demonstrating a central role of PARP1 in these pathologies. In particular, progressive DNA damage and increased PARP1 activity in aging neurons eventually leads to programmed neuronal death and loss of memory consolidation; moreover, PARP1 has been implicated in age-related memory deficits and dementia [13]. Many different proteins, including PARP1 itself, the nuclear factor$\kappa \mathrm{B}(\mathrm{NF}-\kappa \mathrm{B})$ and histones [14], are targets of the poly(ADP-ribosyl)ation reaction. PARP1 has been reported to play a dual role in cell survival and necrosis via induction of autophagy and $\mathrm{NAD}^{+} / \mathrm{ATP}$ depletion, respectively [15]. PARP1 is needed to repair DNA lesions induced by reactive oxygen species, but its expression and activity may increase inflammation via upregulation of NF- $\mathrm{KB}$ signaling [16].

Exposure to environmental/genotoxic stresses leads to $\mathrm{NAD}^{+}$depletion upon concomitant decrease of SIRT1 activity and PARP1 activation [17]. The latter has been shown in different pathological conditions [18], and the presence of PAR polymers has been reported in postmortem brain samples [19], skin fibroblasts, and lymphoblasts from $\mathrm{AD}$ patients [20]. Although the PARP1-AD relationship needs confirmation and mechanistic explanation, previous data indicate that PARP1 activation mediates $A \beta$-induced neuronal death, and deletion or inhibition of PARP1 gene can markedly improve neuronal survival [18]. A crosstalk between SIRT1 and PARP1 does exist; in fact, PARP1 can be acetylated and activated under 
stress conditions whereas PARP1 activity is blocked following SIRT1-dependent deacetylation [21]. On the other hand, PARP1 overactivation suppresses the activity of SIRT1 by reducing cellular $\mathrm{NAD}^{+}$levels, suggesting that the two proteins might be able to counterbalance each other's activity thus controlling the cell survival/cell death equilibrium [21].

Several studies have shown that olive polyphenols affect antioxidant and anti-tumor and other cell activities upon genetic modulation [22]. Here, we sought to further stress the epigenetic correlates of the OLE beneficial effects against neurodegeneration by investigating the activation state of PARP1 and its crosstalk with SIRT1 both in TgCRND8 mice and in N2a cultured cells. In addition, since SIRT1 and PARP1 modulate the activity of both NF- $\mathrm{KB}$ and the p53 tumor suppressor protein [23], we also investigated whether the inhibition of the transcription of these pro-inflammatory and pro-apoptotic proteins by OLE could underlie the beneficial effects of this polyphenol.

\section{MATERIALS AND METHODS}

\section{Ethics statement}

Transgenic CRND8 mice harboring a doublemutant gene of APP695 [24] and wild type (wt) control littermates were used following the ECC (DL 116/92, Directive 86/609/EEC) and National guidelines for animal care. The protocol was approved by the Committee on the Ethics of Animal Experiments of the Italian Ministry of Health (Permit Number: 152/2014-B).

\section{Animals}

4-month-old TgCRND8 and wt mice were used ( $n=6$ /group/genotype, equally divided for sex). The mice were treated for 8 weeks with a modified low-fat (5.0\%) AIN-76A diet (10 g/day per mouse) composed of $50.0 \%$ sucrose, $5.0 \%$ fat, $20.0 \%$ casein, $15.0 \%$ corn starch, $5.0 \%$ powdered cellulose, $3.5 \%$ AIN-76 mineral mix, $1.0 \%$ AIN-76A vitamin mix, $0.3 \%$ DL-methionine, and $0.2 \%$ choline bitartrate (Piccioni, Milan, Italy), either as such (untreated mice) or supplemented with OLE $(50 \mathrm{mg} / \mathrm{kg}$ of diet) (OLE-fed mice), as recently reported [3, 4]. In addition, a group of 1.5-month-old OLE-treated TgCRND8 mice and a group of untreated TgCRND8 or wt mice ( $n=6 /$ group/genotype, equally divided for sex) was used for immunohistochemical and western blotting analysis of PAR polymers only. Paraffinembedded brain slices of 6-month-old OLE-fed wt mice [3] were employed for the analysis of PAR immunoreactivity reported in Fig. 1.

\section{Oleuropein deglycosylation}

Oleuropein (Extrasynthase, Genay Cedex, France) deglycosilation was performed according to Konno et al. [25] with minor modifications [3]. Briefly, a $10 \mathrm{mM}$ solution of glycated oleuropein in $0.1 \mathrm{M}$ sodium phosphate buffer, $\mathrm{pH}$ 7.0, was incubated with 7.55 I.U. $/ \mathrm{mL}$ of $\beta$-glycosidase overnight at room temperature in the dark. The reaction mixture was centrifuged at $10,000 \times \mathrm{g}$ for $15 \mathrm{~min}$ to precipitate the aglycone. The complete oleuropein deglycosylation was confirmed by assaying the glucose released in the supernatant with the Glucose (HK) Assay Kit (Sigma-Aldrich, Milan, Italy). GC-MS analysis showed the absence of any oleuropein in the precipitate and the substantially total recover of OLE in the same precipitate. A 50 or $100 \mathrm{mM}$ OLE stock solution in DMSO was stored protected from light; the solution was diluted immediately before use in seed oil (for mice feeding) or in buffer (for in vitro experiments).

\section{Cell treatments and western blotting analysis}

N2a murine neuroblastoma cells (European Collection of Authenticated Cell Cultures, ECACC) were plated in Eagle's minimum essential medium (MEM) supplemented with non-essential amino acids, 10\% FCS (Sigma-Aldrich, Steinheim, Germany), antibiotics, and glutamine. The cells were maintained in a $5.0 \% \mathrm{CO}_{2}$ humidified atmosphere at $37^{\circ} \mathrm{C}$. To induce protein poly-ADP-ribosylation, the cells were incubated for $15 \mathrm{~min}$ with $100 \mu \mathrm{M}$ of the PARP1 activator methylnitronitrosoguanidine (MNNG). After treatment for $24 \mathrm{~h}$ with OLE $(100 \mu \mathrm{M})$ or with the PARP inhibitors $6(5 \mathrm{H})$-phenanthridinone (PHE, $30 \mu \mathrm{M})$ or $\mathrm{N}$-(6-oxo-5,6-dihydrophenanthridin-2yl)-(N,N-dimethylamino) acetamide hydrochloride (PJ-34, $20 \mu \mathrm{M})$, the cells were lysed in Laemmli buffer $(60 \mathrm{mM}$ Tris- $\mathrm{HCl}, \mathrm{pH} 6.8,2 \% \quad(\mathrm{w} / \mathrm{v})$ SDS, $10 \mathrm{mM}$ EDTA, $10 \%$ (w/v) glycerol) and protein concentration was determined with a BCA detection kit (Pierce, USA). The samples were added with $\beta$-mercaptoethanol and bromophenol blue, boiled for $10 \mathrm{~min}$, clarified at $10,000 \times \mathrm{g}$ for $10 \mathrm{~min}$, run on $8 \%$ SDS-PAGE, and transferred to PVDF membranes (Amersham 
A

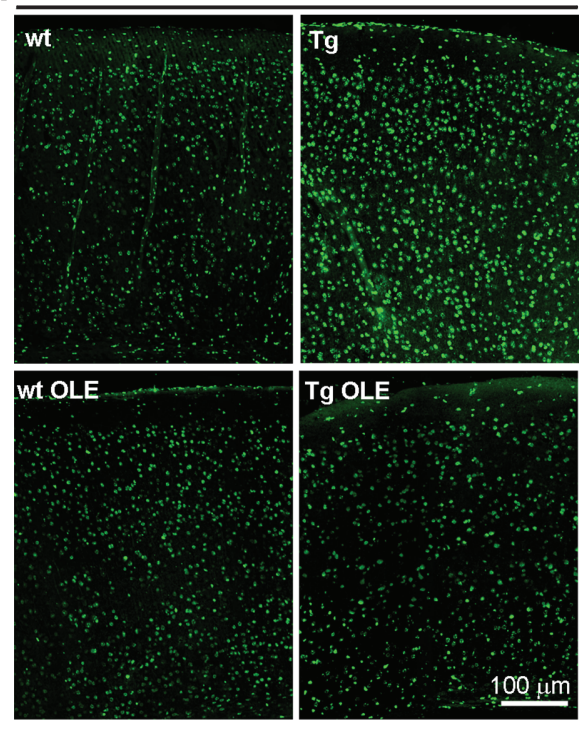

C

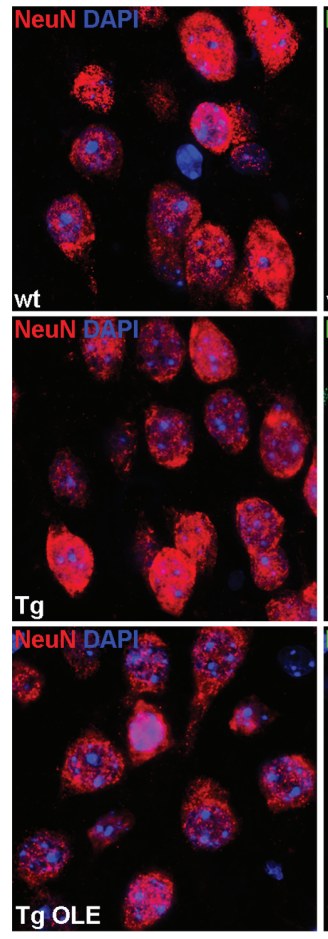

B

Cortex 3.5 months
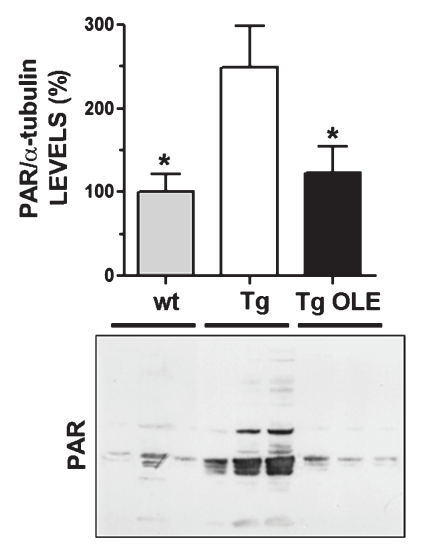

\section{Cortex 6 months}
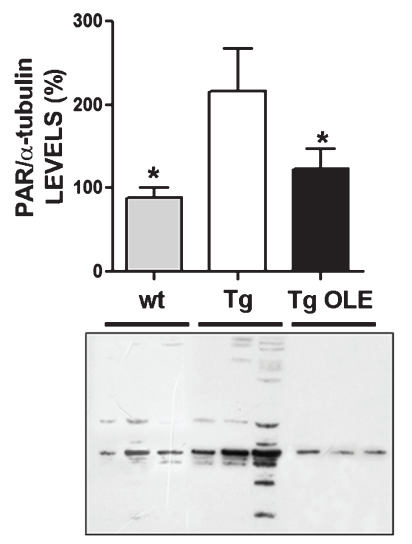

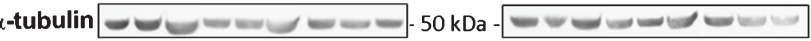
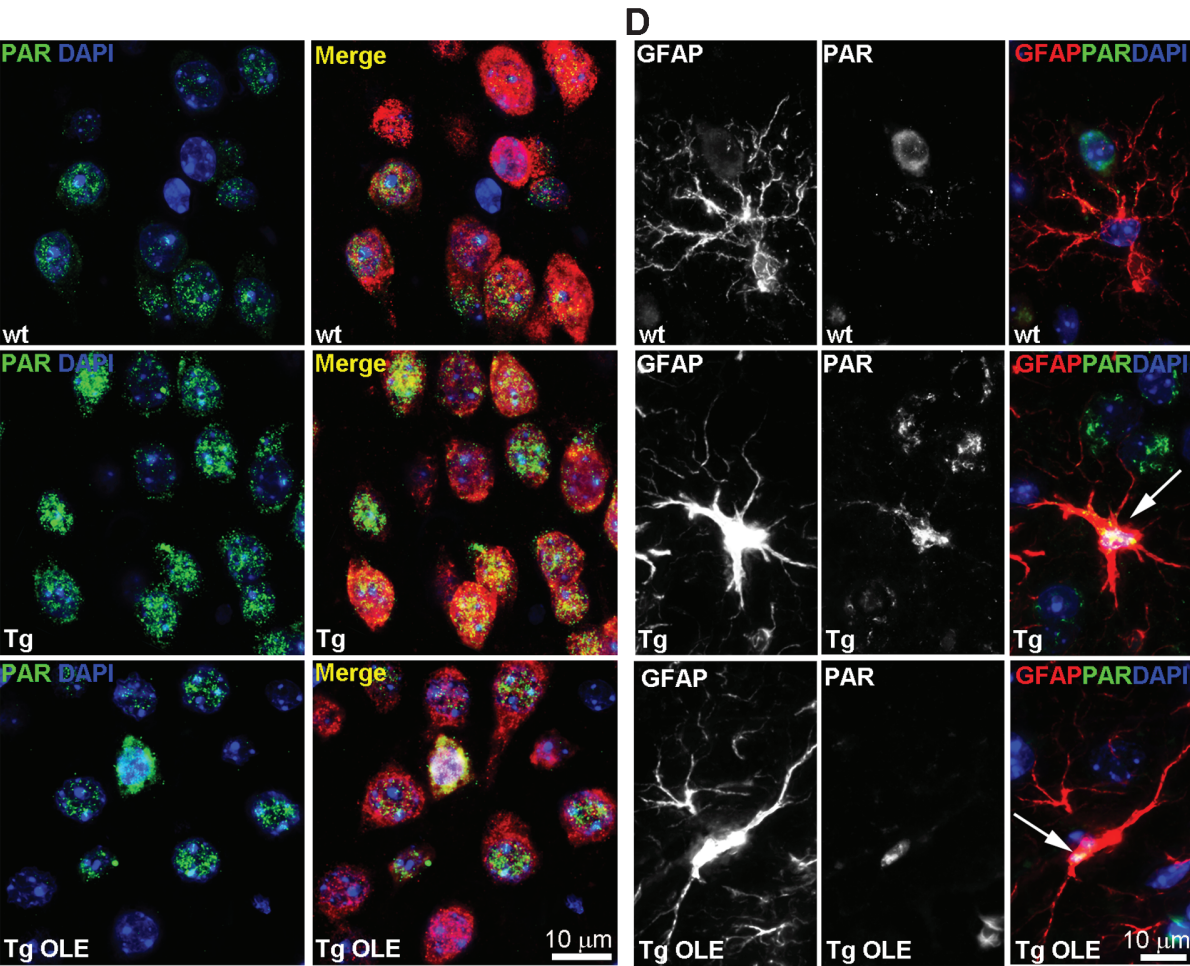

Fig. 1. OLE inhibits PARylation in TgCRND8 mice. A) Representative photomicrographs of PAR immunoreactivity in the cortex of 6month-old mice, note the high PAR immunoreactivity in the cortex of untreated TgCRND8 mice compared to OLE-fed Tg and wt mice. B) Western blotting analysis of PAR protein levels in the cortex of 3.5- and 6-month-old untreated wt and Tg mice and OLE-fed Tg mice. C) Double immunofluorescence with NeuN (red) and PAR (green) antibody and (D) with GFAP (red) and PAR (green) antibody plus DAPI (blue). PAR immunoreactivity is mainly detected within the nucleus of neurons and in a few astrocytes GFAP positive in Tg mice only, as shown in panels on the right (arrows). $n=5-6$ mice/group. ${ }^{*} p<0.05$ versus Tg mice.

GE Healthcare, Buckinghamshire, UK). After blocking with $5.0 \%(\mathrm{w} / \mathrm{v}) \mathrm{BSA}$ in $0.1 \%(\mathrm{v} / \mathrm{v})$ PBSTween-20, the membrane was incubated overnight at $4{ }^{\circ} \mathrm{C}$ with specific primary antibodies (Abs) (Table 1). After washing, the membranes were incubated for $1.0 \mathrm{~h}$ with 1:10000 specific secondary 
Table 1

Antibodies employed in the study

\begin{tabular}{|c|c|c|c|c|c|c|}
\hline \multirow[t]{2}{*}{ Antibody } & \multirow[t]{2}{*}{ Specific } & \multicolumn{2}{|c|}{ Dilution } & \multirow{2}{*}{$\begin{array}{l}\text { Antigen retrieval } \\
\text { for IHC }\end{array}$} & \multirow[t]{2}{*}{ Host } & \multirow[t]{2}{*}{ Source } \\
\hline & & $\overline{\mathrm{WB}}$ & IHC & & & \\
\hline Anti-Poly (ADP-ribose) [PAR] & Poly(ADP-ribose) & $1: 1000$ & $1: 100$ & Citrate Buffer & Mouse & AdipoGen \\
\hline Anti-Poly (ADP-ribose) [PAR] & Poly(ADP-ribose) & ND & $1: 200$ & Citrate Buffer & Rabbit & BD Pharmingen \\
\hline PARP & PARP-1 & $1: 1000$ & ND & & Rabbit & Cell Signaling \\
\hline NeuN & Neuronal Nuclei & ND & $1: 200$ & Citrate Buffer & Mouse & Millipore \\
\hline GFAP & Glial fibrillary acidic protein & ND & $1: 500$ & & Rabbit & Dako \\
\hline Phospho-NF-кB p65 (Ser536) & Phospho-NF-кB p65 (Ser536) & $1: 1000$ & $1: 100$ & Citrate Buffer & Rabbit & Cell Signaling \\
\hline NF-кB p65 & NF-кB p65 & $1: 1000$ & ND & & Rabbit & Cell Signaling \\
\hline Phospho-p53 (Ser46) & Phospho-p53 (Ser46) & $1: 1000$ & $1: 50$ & Citrate Buffer & Rabbit & Cell Signaling \\
\hline $\mathrm{p} 53$ & p53 & $1: 500$ & ND & & Rabbit & Santa Cruz \\
\hline Beclin1 & Beclin1 & $1: 1000$ & ND & & Rabbit & Abcam \\
\hline SIRT1 & SIRT1 & $1: 400$ & ND & & Rabbit & Proteintech \\
\hline$\beta-\operatorname{actin}$ & $\beta-$ actin & $1: 1000$ & ND & & Mouse & Santa Cruz \\
\hline$\alpha$-tubulin (HRP-conjugated) & $\alpha$-tubulin & $1: 5000$ & ND & & Mouse & Proteintech \\
\hline
\end{tabular}

aa, amino acid, WB, western blot; IHC, immunohistochemistry, ND, not done.

goat anti-rabbit and goat anti-mouse Abs (Molecular Probes, Life Technologies). The immunoreactive bands were detected with the Immobilon Western Chemiluminescent HRP substrate (Millipore, Billerica, MA, USA) and quantified by densitometric analysis using a ChemiDoc system and the Quantity One software (Bio-Rad Laboratories, Italy). 1:1000 mouse monoclonal anti- $\beta$-actin Ab (Santa Cruz Biotechnology Inc.) was used for protein load normalization.

\section{N2 a cell treatment and nucleotide measurement}

N2a cells were plated in MEM, 10\% FCS (FCS, Sigma-Aldrich), antibiotics, and glutamine. The cells were treated for $24 \mathrm{~h}$ with $100 \mu \mathrm{M}$ OLE or with $100 \mu \mathrm{M}$ OLE plus $100 \mu \mathrm{M}$ MNNG (90 min). The $\mathrm{NAD}^{+}$levels were measured by means of an enzymatic cycling procedure according to [26]. Briefly, the cells grown in a 48 well plate were killed with $50 \mu \mathrm{l}$ of $1 \mathrm{~N} \mathrm{HClO}_{4}$ and the mixture was neutralized by adding an equal volume of $1 \mathrm{~N} \mathrm{KOH}$. Then, $100 \mu \mathrm{l}$ of cells extract was added with $50 \mathrm{mM}$ bicine $(50 \mu \mathrm{l})$ and mixed with an equal volume of bicine buffer containing $23.0 \mu \mathrm{l} / \mathrm{ml}$ ethanol, $0.17 \mathrm{mg} / \mathrm{ml}$ MTT, $0.57 \mathrm{mg} / \mathrm{ml}$ phenazine ethosulfate, and $20 \mu \mathrm{g}$ alcohol dehydrogenase. The mixture was left standing at room temperature for $10 \mathrm{~min}$ before absorbance measurement at $550 \mathrm{~nm}$.

\section{Animal tissue processing}

At the end of the treatment with OLE, the mice (3.5- and 6-month-old) were sacrificed by cervical dislocation and the brains were rapidly removed and divided sagittally. For protein analysis, cortical and hippocampal samples from one hemibrain were immediately sectioned, snap-frozen and stored at $-80^{\circ} \mathrm{C}$. The other hemibrain was postfixed for $48 \mathrm{~h}$ in phosphate-buffered $4.0 \%$ paraformaldehyde, $\mathrm{pH}$ 7.4 , at $4^{\circ} \mathrm{C}$, rinsed in PBS and embedded in paraffin for immunohistochemistry.

\section{Immunohistochemistry and western blotting}

Immunohistochemistry was performed on $5.0 \mu \mathrm{m}$ coronal paraffin-embedded sections, as previously described [27]. The sections were incubated overnight at $4{ }^{\circ} \mathrm{C}$ with the primary $\mathrm{Ab}$ (Table 1) diluted in $0.1 \mathrm{M} \mathrm{PBS}, \mathrm{pH} 7.4$, containing $0.3 \%$ Triton $\mathrm{X}-100$ and $5.0 \mathrm{mg} / \mathrm{mL}$ BSA. On day 2 , the sections were incubated for $1.0 \mathrm{~h}$ in the dark with the appropriate fluorescent secondary Ab (Alexa Fluor 594- or 488- conjugated monoclonal anti-mouse and polyclonal anti-rabbit Ab; Invitrogen, New York, USA) diluted 1:400. For double immunostaining, the sections were incubated overnight with the second primary $\mathrm{Ab}$ in the dark at $4{ }^{\circ} \mathrm{C}$ and, on day 3 , for $1.0 \mathrm{~h}$ at room temperature with the second fluorescent $\mathrm{Ab}$ diluted 1:400 in BS. The analysis of negative controls (not treated with the primary $\mathrm{Ab}$ ) was simultaneously performed to exclude the presence of non-specific immunofluorescence staining, crossimmunostaining, or fluorescence bleed-through.

For western blotting analysis, tissue and cell samples were homogenized in ice-cold RIPA lysis buffer; then, $40 \mu \mathrm{g}$ of proteins was applied to $4-12 \%$ Criterion XT Bis-Tris Gel (Novex NuPAGE, Lyfe Technologies, New York, USA) for electrophoresis 
with XT MOPS running buffer (Lyfe Technologies, New York, USA). The separated proteins were transferred onto $0.2 \mu \mathrm{m}$ nitrocellulose membrane by the iBlot dry blotting system (Invitrogen, New York, USA) and incubated overnight at $4^{\circ} \mathrm{C}$ with the primary Ab (see Table 1). The day after, the blots were incubated for $1.0 \mathrm{~h}$ with the HRP-conjugated secondary Ab (Thermo Scientific, Waltham, MA, USA) diluted 1:4000 in BS. The immunocomplexes were visualized by enhanced chemiluminescence (Amersham ECL, GE Healthcare, Buckinghamshire, UK) and acquired using the ImageQuant 350 system (GE Healthcare, Buckinghamshire, UK). Densitometric band analysis was performed using the Image Quant TL software (GE Healthcare, Buckinghamshire, UK). The bands were normalized to the respective housekeeping protein or to $\alpha / \beta$ tubulin. All concentrations of primary Ab were titrated to provide optimal staining (Table 1).

\section{Real-time PCR}

Total RNA was isolated from wild type or transgenic mouse treated or not with OLE, as described above, by the RNeasy mini kit (Qiagen, Germany), subjected to RNase-free DNase digestion (Ambion, USA) and analyzed spectroscopically. $1.0 \mu \mathrm{g}$ of RNA was retro-transcribed using iScript ${ }^{\mathrm{TM}}$ (BioRad, USA) and amplified with specific primers, as described below. For mouse PARP1 mRNA: forward 5'-CACTCTGCACACGTCCTGGAGAAAG-3', reverse 5'-GGAGGGCATCTGCTCAAGTTTGTT AC-3'; for 18S rRNA: forward 50-AAAACCAA CCCGGTGAGCTCCCTC-30, reverse 50-CTCAGG CTCCCTCTCCGGAATCG-30. All primers were purchased from IDT (IDT, Germany). PCR amplification was performed by means of SSOADV UNIVER SYBR SMX (Bio-Rad, USA) according to manufacturer instruction. PCR amplification of $18 \mathrm{~S}$ rRNA was used as the normalizer. Real-time PCR assays were performed using the Rotorgene 6000 cycler system (Qiagen, Germany).

\section{Data analysis}

Statistical analysis was performed using One way ANOVA followed by Bonferroni post hoc test and the significance was defined as $p<0.05$. Data are reported as mean \pm standard error of the mean (S.E.M).

\section{RESULTS}

\section{Effects of OLE on PARPl activation in TgCRND8 mice}

PARP1 activation generates PAR polymers [28]. Comparable PARP1 activity enhancement and PAR accumulation have been reported in AD patients, particularly in neurons of the frontal and temporal lobes [19], in the brain of transgenic TASTPM AD mice [18] and in the hippocampus of 3-monthold TgCRND8 mice [29]. Thus, we firstly searched for the presence of PAR polymers in the frontal cortex of untreated or OLE-fed 3.5- and 6-monthold TgCRND8 or wt mice. Two age groups were employed to assess whether PARylation occurred at 3.5 months of age, the early stage of $A \beta$ deposition [24] and/or at 6 months of age, the intermediate stage of $A \beta$ deposition [3]. In both age groups, PAR immunoreactivity was higher in the cortex of TgCRND8 mice respect to wt mice, as exemplified in 6-month-old animals, whereas PAR polymers were markedly reduced in the cortex of 6-month-old OLEfed $\mathrm{Tg}$ mice with respect to untreated $\mathrm{Tg}$ mice of the same age (Fig. 1A). The western blotting analysis confirmed these data, showing a significant increase in PAR polymer levels in the frontal cortex of 3.5and 6-month-old Tg animals compared to wt mice of the same age (Fig. 1B), whereas in OLE-fed Tg animals of both ages PAR polymer levels were similar to those found in wt mice.

Next, we sought to identify the type of cells displaying accumulation of PAR polymers by double immunofluorescence staining using antibodies to NeuN (red) and to PAR (green) and antibodies to GFAP (red) and to PAR (green) plus DAPI (blue). In Tg and wt animals, PAR immunoreactivity was found mainly within neuronal nuclei, as shown by the positive staining with NeuN antibody plus DAPI (Fig. 1C), whereas it was also detected within a few astrocytes only in Tg groups, as shown by GFAP antibody staining (arrows in the merged images of Fig. 1D). Notably, the number of PAR-immunopositive neurons detected in TgCRND8 mice was strongly reduced in OLEfed Tg mice, confirming a possible inhibition of PARP1 activation by OLE (Fig. 1C). Overall, these data indicate that, in TgCRND8 mice, OLE reduces PARP1 activation and PAR polymers to the values found in wt mice, suggesting possible protection against PAR accumulation also in $\mathrm{AD}$ people. 
OLE inhibits MNNG-induced PARPI activation and attenuates $N A D^{+}$depletion in N2a cells

To confirm inhibition of PARP1 activation by OLE in the mouse brain, we determined the levels of PARylated proteins in cultured N2a neuroblastoma cells exposed for $15 \mathrm{~min}$ to $100 \mu \mathrm{M}$ MNNG, a PARP activator, in the absence or in the presence of $100 \mu \mathrm{M}$ OLE or of two PARP inhibitors (PHE, $30 \mu \mathrm{M}$ or PJ-34, $20 \mu \mathrm{M}) 24 \mathrm{~h}$ prior to treatment with MNNG. As expected, we found that MNNG induced a significant increase of PARylated proteins with respect to untreated control cells (Fig. 2A). However, the MNNG-induced PAR formation was markedly reduced in cells treated with OLE, PHE, or PJ-34 $24 \mathrm{~h}$ prior to MNNG exposure, where PAR levels dropped below control values. At the same conditions, cell treatment with OLE, PHE, or PJ-34 alone did not affect PAR formation.

PARP activity needs $\mathrm{NAD}^{+}$as a substrate and contributes to the modulation of intracellular $\mathrm{NAD}^{+}$ levels. Therefore, we measured $\mathrm{NAD}^{+}$content in $\mathrm{N} 2 \mathrm{a}$ cells exposed to MNNG $(100 \mu \mathrm{M})$ for $90 \mathrm{~min}$ to confirm the above reported data. At these conditions, we found a significant reduction $(-27 \%)$ of the $\mathrm{NAD}^{+}$ content as compared to the levels measured in control cells. Such a reduction was slightly attenuated by cell treatment for $24 \mathrm{~h}$ with $20 \mu \mathrm{M}$ PJ-34 or with $100 \mu \mathrm{M}$ OLE (Fig. 2B). Treatment with OLE did not affect $\mathrm{NAD}^{+}$levels in control cells (not shown). Taken together, these data indicate that OLE administration to cultured neuronal cells displays effects similar to those elicited by PARP inhibitors contributing to explain PAR decrease in OLE-fed Tg mice.

\section{OLE reduces PARP1 expression and modulates the PARP1-SIRT1 interplay in 6-month-old TgCRND8 mice}

Since PARP1 accounts for over $85 \%$ of nuclear PARP activity [30], we next investigated PARP1 expression levels in 6-month-old Tg mice normally fed or supplemented with OLE by determining PARP1 mRNA levels. As expected, the PARP1 mRNA levels in the cortex of Tg mice were over 4 times higher than in the cortex of wt mice but were fully rescued to those of wt mice upon OLE treatment (Fig. 3A). These data matched those relative to the PARP1 protein levels; in fact, in the cortex of TgCRND8 mice we found a roughly $100 \%$ increase of the $116 \mathrm{kDa}$ PARP1 (the uncleaved protein) and over a $100 \%$ increase of the $89 \mathrm{kDa}$ PARP1 (the caspase 3-cleaved fragment) as compared to wt mice (Fig. 3B). However, in OLE-fed Tg mice the levels of the $116 \mathrm{kDa}$ and $89 \mathrm{kDa}$ proteins were maintained to the values found in wt mice. These data indicate that, in our Tg model, diet supplementation with OLE results in a significant decrease of PARP1 expression, which explains both PARP1 activation reduction and the lowered levels of PARylated proteins; they also provide clues to explain OLE protection against apoptotic cell death induced by PARP1 fragments generate by caspase 3 [31].

A functional link between PARP1 and SIRT1 has been reported, and previous data show that PARP1 activation with ensuing $\mathrm{NAD}^{+}$reduction results in SIRT1 inhibition [8]. Therefore, we investigated the expression of SIRT1 in the cortex of our TgCRND8 mice, its co-localization with PARP1 and its modulation by OLE. We found that SIRT1 immunoreactivity was strongly reduced in the cortex of TgCRND8 mice as compared to wt mice and that, similarly to the effect of other polyphenols [8], OLE treatment increased its expression in Tg mice (Fig. 3C). In line with the immunohistochemical data, quantitative analysis showed a significant reduction of SIRT1 in Tg mice as compared to wt mice while it appeared markedly increased in OLE-treated $\mathrm{Tg}$ mice (Fig. 3D). Double labeling fluorescent immunohistochemistry with PARP1 (green) and SIRT1 (red) antibodies plus DAPI (blue) revealed co-localization between PARP1 and SIRT1 (Fig. 3E, yellow color) in all groups of animals, irrespective of treatment and genotype; however, as reported above for PAR, PARP1 was expressed in Tg mice at higher levels than in wt animals, whereas it expression was reduced in OLE-treated mice. Altogether, these data indicate that OLE treatment increases the expression of SIRT1 and reduces that of PARP1, confirming the ability of this polyphenol to interfere with the functional link between PARP1 and SIRT1.

\section{OLE increases SIRTlexpression in N2a cells}

Our previous studies in TgCRND8 mice and in cultured cells showed that OLE administration results in the activation of the autophagy-lysosome system [3, $32]$ and decreases the expression of histone deacetylase 2 (HDAC2), with ensuing increase of histone acetylation [4]. On the other hand, it is known that polyphenols activate SIRT1 which, in turn, stimulates autophagy and thereby mimics caloric restrictionmediated lifespan extension [33]. It is also known that PARP1, besides playing a role in cell death, 
A

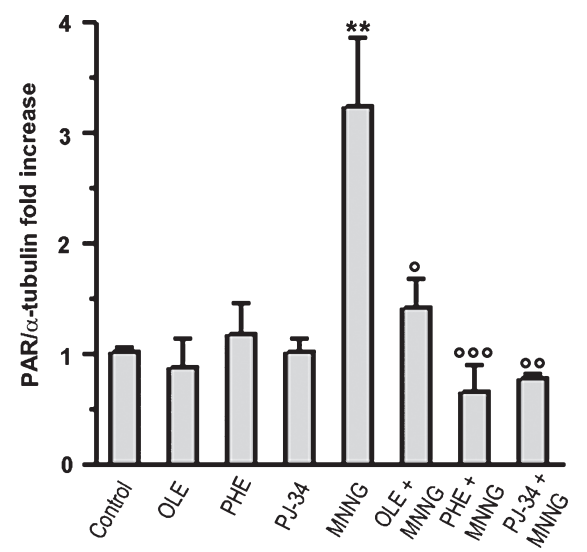

B

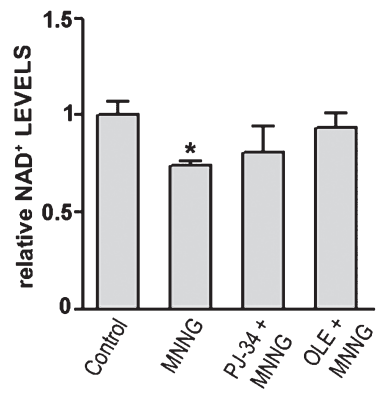

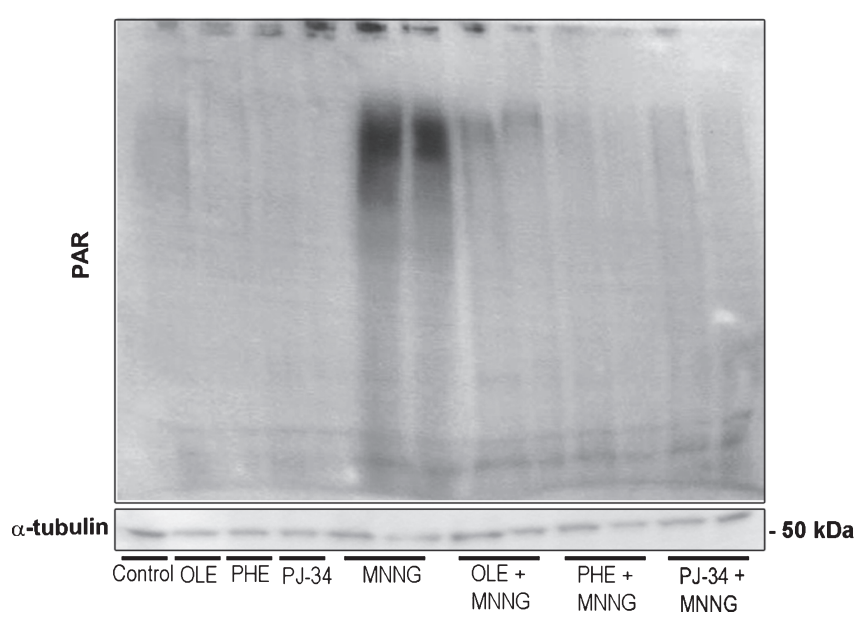

Fig. 2. OLE inhibits PARP1 activation and attenuates NAD ${ }^{+}$levels in N2a cells exposed to MNNG. N2a cells were exposed to MNNG for 15 min then, PARylated proteins were detected by immunoblotting (A). MNNG-induced PARylation in inhibited by cell treatment with OLE, PHE, or PJ-34 $24 \mathrm{~h}$ prior to MNNG exposure. OLE, PHE, and PJ-34 treatment does not affect PARylated protein levels. B) NAD ${ }^{+}$ levels in N2a cells treated with MNNG for 90 min alone or in combination with PJ-34 or OLE, $24 \mathrm{~h}$ prior to MNNG exposure. A) ${ }^{\circ} p<0.05$, ${ }^{\circ 0} p<0.01$, and ${ }^{\circ 00} p<0.001$ versus MNNG treated cells; ${ }^{* *} p<0.01$ versus controls. B) ${ }^{*} p<0.05$ versus control cells.

can also induce cell survival via autophagy stimulation [15]. Therefore, we investigated in N2a cells (i) the effect on SIRT1 expression of cell treatment for $24 \mathrm{~h}$ with $100 \mu \mathrm{M}$ OLE (Fig. 4A) and (ii) the effect on Beclin1, a protein involved in the initiation and execution of autophagy, levels of cell treatment with $100 \mu \mathrm{M}$ MNNG for $15 \mathrm{~min}$ or of cell treatment for $24 \mathrm{~h}$ with $100 \mu \mathrm{M}$ OLE prior to exposure to $100 \mu \mathrm{M}$ MNNG for $15 \mathrm{~min}$ (Fig. 4B). We found that, in OLE-treated cells, SIRT1 levels were increased by over $250 \%$, as compared to control cells, and that Beclin1 levels were increased by around $100 \%$ upon MNNG exposure and by roughly $200 \%$ in cells treated with OLE prior to MNNG exposure. Altogether, these findings indicate that PARP1 activation by MNNG results in protein PARylation and increased autophagy, in agreement with previous data
[34], and that OLE increases SIRT1 expression and synergizes with MNNG as an autophagy trigger.

\section{$N F-\kappa B$ expression is reduced in OLE-treated TgCRND8 mice}

PARP1 activation can influence brain injury and neuronal death through modulation of the brain inflammatory response; these effects are largely mediated by its interactions with the nuclear transcription factor NF- $\mathrm{kB}[35,36]$, whose abnormal activation is involved in AD [37]. Therefore, in the light of the anti-inflammatory activity of OLE previously reported [3, 38], we investigated in TgCRND8 mice whether a reduction of the phospho (p)-NF$\kappa \mathrm{B}$, the protein form that migrates to the nucleus, matched OLE-induced PARP1 inhibition. By double 
A

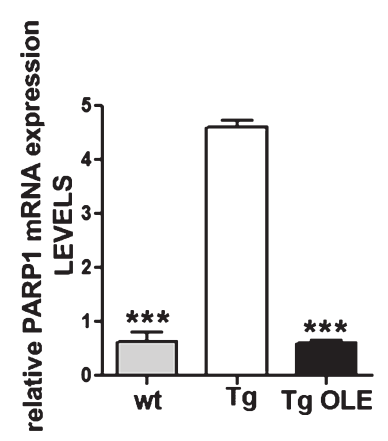

B

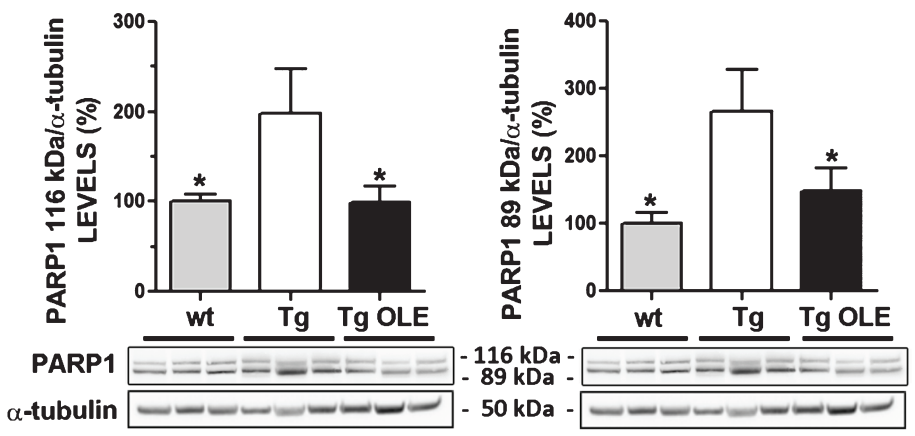

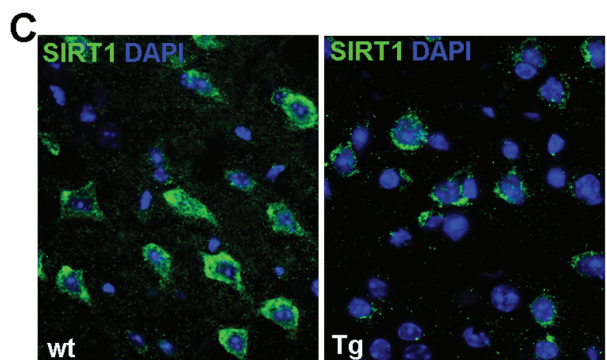

E

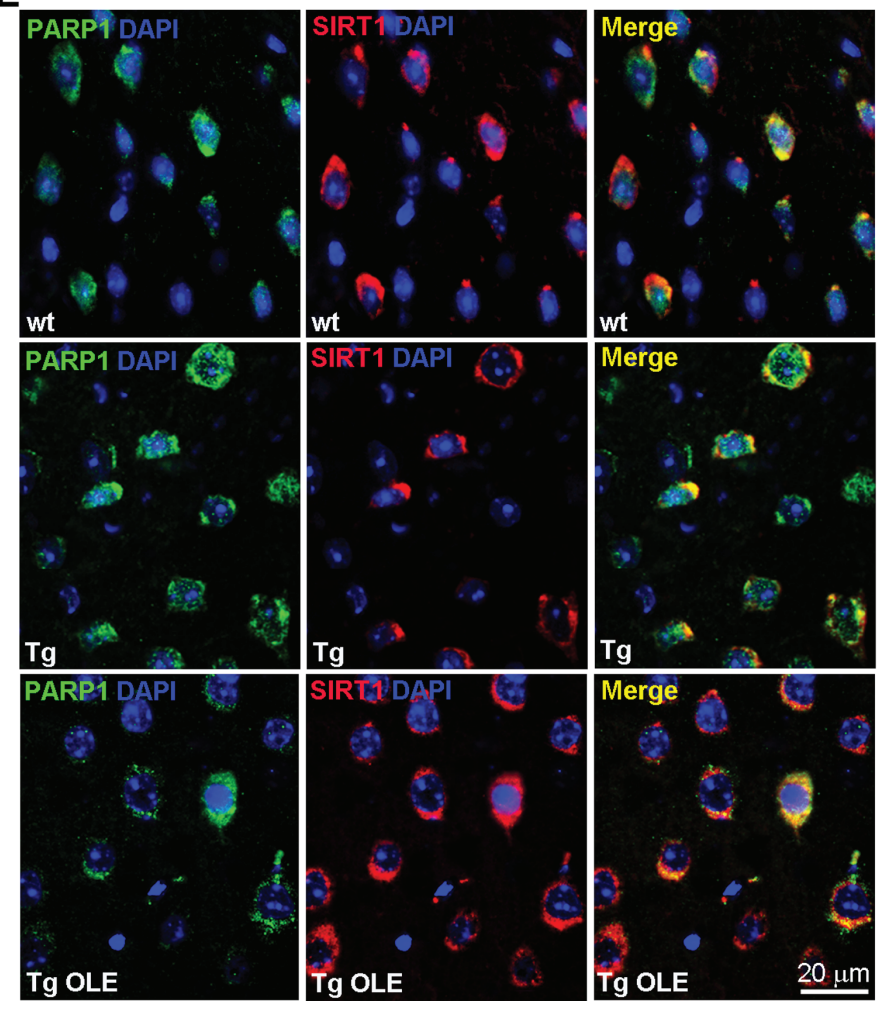

D
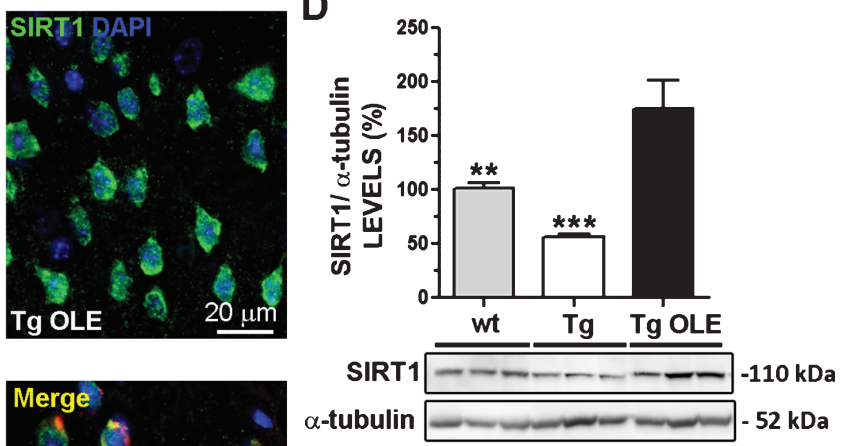

Fig. 3. OLE decreases PARP1 expression and increases SIRT1 expression in 6-month-old TgCRND8 mice. A) PARP1 mRNA levels and (B) western blotting analysis of PARP1 protein levels in the cortex of 6-month-old OLE-fed Tg mice and untreated wt and Tg mice. C) Immunofluorescence with SIRT1 (green) antibody plus DAPI (blue). SIRT1 immunoreactivity is localized mainly at perinuclear and nuclear levels. D) Western blotting analysis of SIRT1 protein levels in OLE-fed Tg mice and untreated wt and Tg mice. E) Double immunofluorescence with PARP1 (green) and SIRT1 (red) antibody plus DAPI (blue). $n=5-6$ mice/group. A) ${ }^{* * *} p<0.001$ versus Tg mice. B) ${ }^{*} p<0.05$ versus Tg mice. D) ${ }^{* *} p<0.01$ and ${ }^{* *} p<0.001$ versus OLE-fed Tg mice. 
A

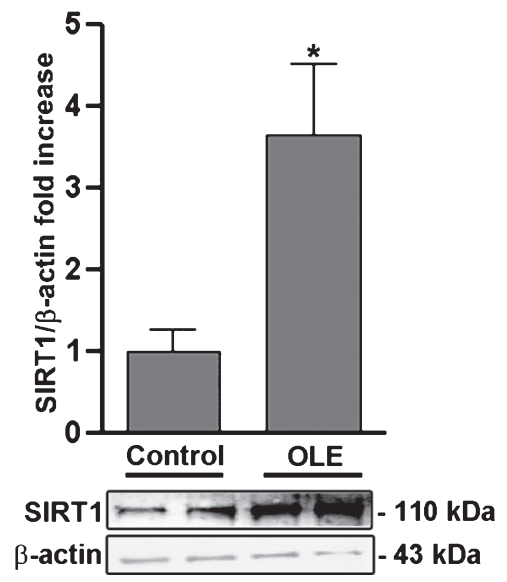

B

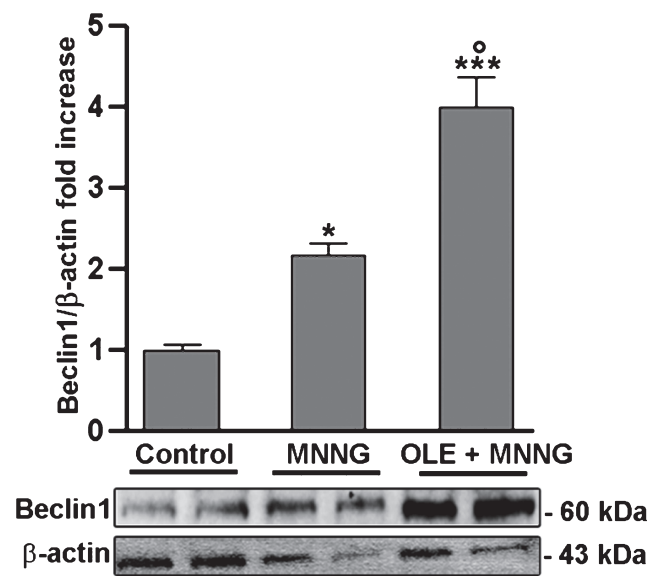

Fig. 4. OLE promotes SIRT1 and Beclin1 expression in N2a cells. A) N2a cells were treated with $100 \mu \mathrm{M}$ OLE for $24 \mathrm{~h}$, then SIRT1 expression was detected by immunoblotting. B) Beclin1 protein levels in N2a cells exposed to $100 \mu \mathrm{M}$ of OLE for $24 \mathrm{~h}$ plus MNNG $100 \mu \mathrm{M}$ for 15 min. A) ${ }^{*} p<0.05$ OLE treated cells versus control cells; B) ${ }^{*} p<0.05$ MNNG treated cells versus control cells; ${ }^{* * *} p<0.001$ OLE + MNNG-treated cells versus control cells; ${ }^{\circ} p<0.01$ OLE + MNNG-treated cells versus MNNG-treated cells.

immunofluorescent staining with anti-p-NF- $\mathrm{B}$ (red) and anti-PAR (green) Abs plus DAPI (blue), we found that the high expression of $\mathrm{p}-\mathrm{NF}-\kappa \mathrm{B}$, detected in the cortex of 6-month-old TgCRND8 mice mainly at the perinuclear and nuclear levels fully co-localized with PAR-immunopositive polymers (Fig. 5A). However, in OLE-fed TgCRND8 mice p-NF- $\mathrm{BB}$ immunoreactivity was drastically reduced and no, or very low, p-NF-кB immunoreactivity was detected, similarly to the expression found in wt mice. The western blotting quantitative analysis showed a significant increase of p-NF- $\mathrm{BB}$ in the cortex of TgCRND8 mice as compared to wt mice, whereas it was significantly reduced to the values of wt animals in OLE-treated Tg mice (Fig. 5B), in agreement with the reported anti-inflammatory effect of OLE.

\section{OLE reduces $p 53$ expression in the cortex of 6-month-old TgCRND8 mice}

PAR polymers are involved in both cell life and death [28] and we found that the cleaved PARP1 89 $\mathrm{kD}$ pro-apoptotic fragment is increased in the cortex of TgCRND8 mice (see Fig. 3B). Modifications of the cellular levels of p53, a transcriptional activator that senses cellular stresses and is up-regulated during DNA damage, hypoxia and oxidative stress, have been associated with neuronal damage both in in vivo and in vitro models [39] as well as with neurodegenerative disorders [40]. p53 activation can lead to either cell cycle arrest and DNA repair or to apoptosis [41]. p53 is phosphorylated at multiple sites and its phosphorylation at Ser46 regulates its pro-apoptotic power [42]. We therefore investigated in TgCRND8 mice the relation, if any, between PARP, apoptosis and phosphorylated p53 and any interference of OLE administration with these processes.

In double immunofluorescence staining with both p53 phosphorylated at Ser 46 (p53 S46) (red) and PAR (green) Abs plus DAPI (blue) we found a strong co-localization between PAR and $\mathrm{p} 53 \mathrm{~S} 46$ immunoreactivity in the neurons of cortex of TgCRND8 mice, as compared to wt mice (Fig. 6A). Remarkably, the intense p53 S46 immunoreactivity and its colocalization with PAR staining detected in TgCRND8 mice was significantly reduced in OLE-fed Tg mice. These immunohistochemical data were confirmed by the analysis of p53 S46 levels; in fact, we found that the significant increase of p53 S46 levels detected in the cortex of TgCRND8 mice respect to wt mice, dropped to the wt values in OLE-fed Tg mice (Fig. 6B). These findings indicate that in our models OLE protects neuronal cells against apoptosis by interfering with the PARP/apoptosis/phosphorylated p53 relation.

\section{DISCUSSION}

PARP1 activation contributes the cascade of events initiated by $A \beta$ increase and aggregation eventually culminating with neuronal cell death [18]; moreover, in the $\mathrm{AD}$ brain it may represent, together with oxidative stress, an early event in disease pathogenesis [19]. 
A

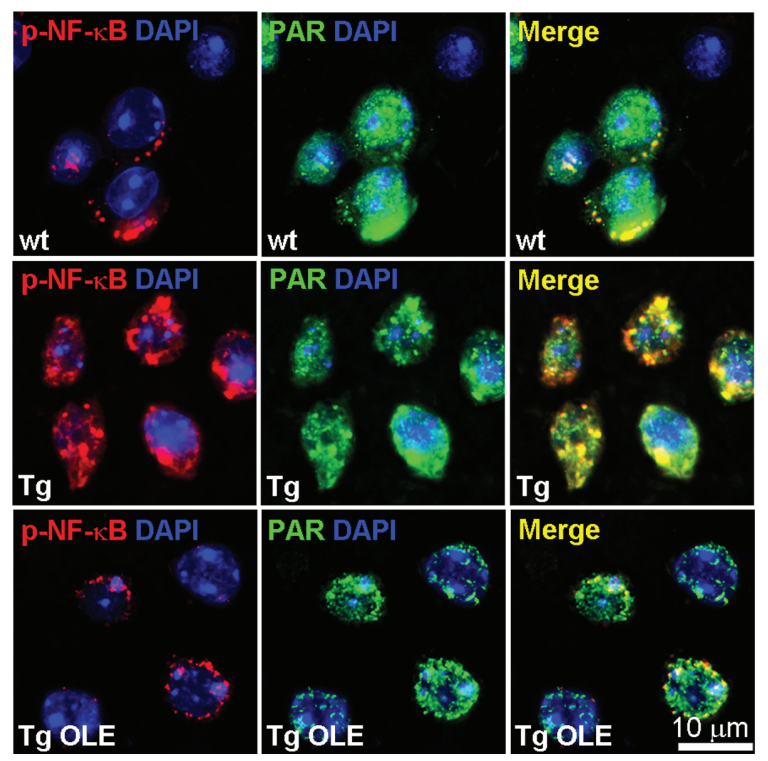

B

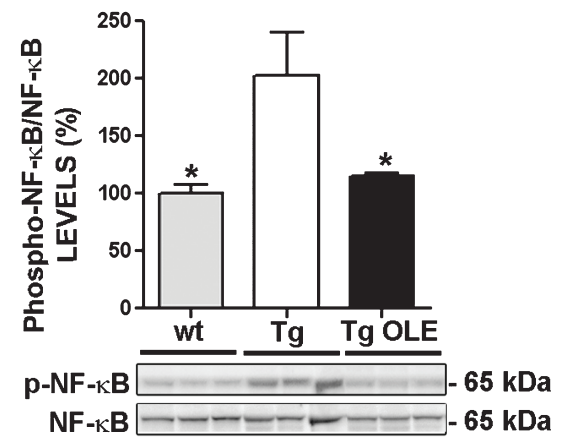

Fig. 5. OLE reduces p-NF- $\mathrm{B}$ expression in 6-month-old TgCRND8 mice. A) Double immunofluorescence with p-NF- $\mathrm{B}$ (red) and PAR (green) antibodies plus DAPI (blue). Note, the perinuclear and nuclear intense fluorescence of $\mathrm{p}-\mathrm{NF}-\kappa \mathrm{B}$ fully co-localizes with PAR polymers in untreated TgCRND8 mice compared to untreated wt and OLE fed Tg mice. B) Western blotting analysis of p-NF- $\mathrm{kB}$ levels versus total NF-кB levels in OLE-fed Tg mice and untreated wt and Tg mice. $n=5-6$ mice/group. ${ }^{*} p<0.05$ versus Tg mice.

A

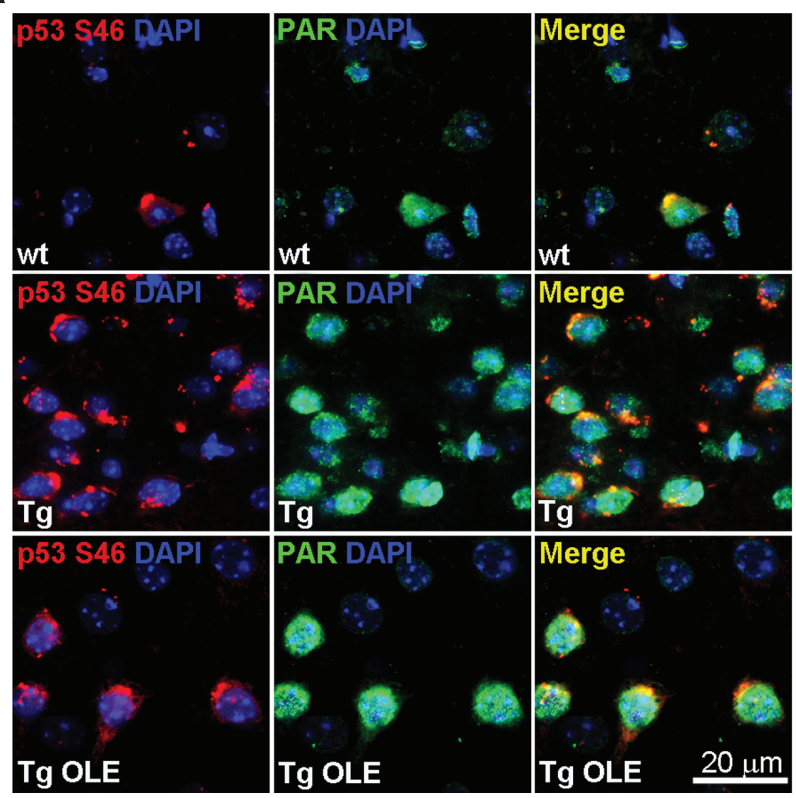

B

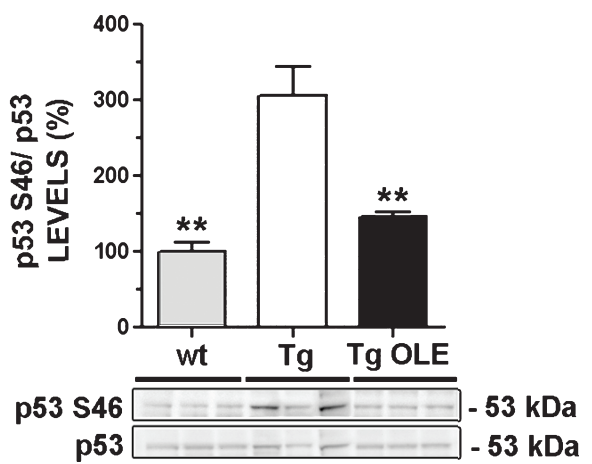

Fig. 6. OLE reduces p53 S46 expression in 6-month-old TgCRND8 mice. A) Double immunofluorescence with p53 S46 (red) and PAR (green) antibodies plus DAPI (blue). Note, in untreated TgCRND8 mice, an high number of immunopositive cells for p53 S46 Ab mainly localized at perinuclear and nuclear levels and fully colocalized with PAR polymers, compared to untreated wt mice and OLE-fed Tg mice. B) Western blotting analysis of p53 S46 protein levels versus total p53 levels in OLE-fed Tg mice and untreated wt and Tg mice. $n=5-6$ mice/group ${ }^{* *} p<0.01$ versus Tg mice. 
PARP1 plays a critical role in keeping DNA integrity and its increased activity in response to DNA damage results in a significant reduction of $\mathrm{NAD}^{+}$levels [11]. A significant accumulation of PAR polymers matching a significant increase of PARP1 activation following its enhanced expression were detected in the cortex of our transgenic CRND8 mouse model of $\mathrm{A} \beta$ deposition at the early (3.5 months) and intermediate (6 months) stage of $A \beta$ deposition. As already reported in AD brain [19], we mostly found PAR and PARP1 immunoreactivities within neurons and, limited to Tg mice, in a few astrocytes. However, OLE treatment for 8 weeks of 6-month-old TgCRND8 mice rescued both PARP1 activation and the accumulation of its product, PAR to the values found in wt mice. In N2a neuroblastoma cells, PARP1 activation and PAR formation induced by cell exposure to the alkylating agent MNNG were abolished by $24 \mathrm{~h}$ pretreatment with either OLE or PARP inhibitors (PHE and PJ-34). These data were confirmed by the determination of $\mathrm{NAD}^{+}$levels in $\mathrm{N} 2 \mathrm{a}$ cells exposed to MNNG, either alone or in association with PJ-34 or OLE; the data obtained with OLE led us to establish whether OLE could behave as an inhibitor of PARP1. The significant reduction of $\mathrm{NAD}^{+}$levels by exposure of N2a cells to MNNG for $90 \mathrm{~min}(27 \%)$ was not reverted significantly by cell treatment for $24 \mathrm{~h}$ with the PARP inhibitor PJ-34 (-20\% n.s) nor by OLE $(-7 \%)$. This finding was likely due to the existence of pleiotropic mechanisms affecting $\mathrm{NAD}^{+}$ levels. That OLE treatment resulted in a reduced tendency to control $\mathrm{NAD}^{+}$levels in MNNG-exposed cells did not support our starting hypothesis that OLE might be a direct inhibitor of PARP1. Accordingly, in N2a cells, the lack of significant reversion by OLE of the reduction of cellular $\mathrm{NAD}^{+}$levels following PARP1 activation by MNNG, likely reflected $\mathrm{NAD}^{+}$ utilization for OLE-induced SIRT1 activation. In fact, OLE treatment enhanced SIRT1 expression both in cultured cells and in Tg mice. Actually, the modest reduction of PARP1 activation in OLE-treated cells might be an indirect downstream event of the increased SIRT1 expression induced by OLE, with concomitant activation of autophagy, reduction of the pro-inflammatory (NF-кB) and pro-apoptotic (p53) markers and decreased PARP1 activation [21]. In turn, SIRT1 can suppress the activity of the PARP1 gene promoter, resulting in decreased PARP1 synthesis which helps cells survival under mild stress conditions [21]. By contrast, under severe stress conditions, $\mathrm{NAD}^{+}$depletion beyond a critical threshold inhibits the activity of SIRT1, with hyperacetylation of target proteins, including p53, Ku70, and PARP1, eventually resulting in cell death [21].

Our previous studies both in vitro with cultured cells [32] and in TgCRND8 mice [3, 38] together with the present study in $\mathrm{N} 2 \mathrm{a}$ cells indicate that OLE is a strong activator of autophagy. Autophagy is a basic mechanism to support cellular homeostasis under stress conditions as well as a survival strategy; however, autophagy can also be associated with programmed cell death [43, 44]. Furthermore, it has been reported that autophagy might be cytoprotective in response to DNA damaging agents and that PARP1 activation is involved in the regulation of this process [45]. Accordingly, we found that in N2a cells the expression of Beclin1, an early autophagosome marker, was increased by over $200 \%$ following cell exposure to MNNG for $15 \mathrm{~min}$, and markedly increased by cell pretreatment with OLE for $24 \mathrm{~h}$ prior to exposure to MNNG. The OLE-induced increase of Beclin1 levels in N2a cells exposed to MNNG might be related to the enhanced intracellular calcium levels, as previously reported in cells treated with MNNG [46] or with OLE [32]. Collectively, our data indicate that PARP1 activation triggers both the apoptotic and the autophagic machineries and that only the latter is further stimulated by OLE treatment. Interestingly, the pro-autophagic effects of both MNNG and OLE apparently proceed through AMPK [32, 34]. Moreover, since OLE increases SIRT1 levels and autophagy is further increased in cells exposed to MNNG plus OLE, our data highlight SIRT1 activation as another mechanism of autophagy stimulation by OLE in addition to that previously reported proceeding both through the $\mathrm{Ca}^{2+}$-CaMKK $\beta$-AMPK-mTOR axis [32] and through epigenetic mechanisms [4].

The crosstalk between PARP1 and SIRT1 suggest that the increased activity of one protein might interfere with the activity of the other [8]. Moreover, PARP1 was shown to enhance the transcription of NF- $\kappa$ B activity, while SIRT1 was found to inhibit NF- $\kappa$ B activity [47, 48]. The functional activity of p53, similarly to NF- $\mathrm{B}$, has been shown to be regulated oppositely by PARP1 and SIRT1 [49, 50]. Our experiments agree with this view, indicating that the activities of the two proteins are also oppositely regulated by OLE. Thus, the increased SIRT1 expression following OLE treatment might underlie the decreased PARP1 expression and the PARP1-mediated increases of NF- $\mathrm{KB}$ and $\mathrm{p} 53$. As far as the latter is concerned, SIRT1 activation was found to interfere with the interaction between 
apoptosis-inducing factor (AIF) and p53 and to favor deacetylation of the p53 C-terminal regulatory domain thus inhibiting its pro-apoptotic power [8]. Notably, in our OLE-fed TgCRND8 mice we found that the $89 \mathrm{kDa}$ PARP1-cleaved protein was significantly reduced respect to the levels found in wt mice. Caspase-3 has been identified as a key mediator of programmed cell death in neurons; moreover, PARP1 cleavage by caspase- 3 is considered an hallmark of apoptosis and has been implicated in several neurological diseases including cerebral ischemia, AD, multiple sclerosis, Parkinson's disease, traumatic brain injury, and others [31]. Accordingly, our data lead to suggest that, in neuronal cells, OLE can interfere inversely with the autophagic and the apoptotic programs.

In conclusion, our in vitro and in vivo study highlights the existence of a complex interplay between OLE, apoptosis, autophagy, SIRT1, and PARP1 activity. In particular, we here report for the first time that, in addition to autophagy, OLE interferes with the PARP1-mediated cascade of events leading both to apoptotic neuronal cell death via p53, to the inflammatory response via NF- $\mathrm{BB}$ induction, and to increased autophagy via increased SIRT1 activity, further favoring cell survival. These findings implement and extend our previously reported data providing a new mechanism of neuroprotection by OLE with possible implications in AD.

\section{ACKNOWLEDGMENTS}

We thank Dr. P. St. George-Hyslop and Dr. D. Westaway for supplying the TgCRND8 mouse strain. This work was supported by the Regione Toscana: "Programma per la Ricerca Regionale in Materia di Salute 2009", by the ECRF 2010-2011 and the Universitá degli Studi di Firenze. M. Stefani was supported by ECRF 2014 and L. Cavone by GR2011-02352225

Authors' disclosures available online (http://j-alz. com/manuscript-disclosures/16-0471r1).

\section{REFERENCES}

[1] Haass C (2004) Take five-BACE and the gamma-secretase quartet conduct Alzheimer's amyloid beta-peptide generation. EMBO J 23, 483-488.

[2] Hayden EY, Teplow DB (2013) Amyloid beta-protein oligomers and Alzheimer's disease. Alzheimers Res Ther 5,60 .

[3] Grossi C, Rigacci S, Ambrosini S, Ed Dami T, Luccarini I, Traini C, Failli P, Berti A, Casamenti F, Stefani M (2013)
The polyphenol oleuropein aglycone protects TgCRND8 mice against $\mathrm{A} \beta$ plaque pathology. PLoS One 8, e71702.

[4] Luccarini I, Grossi C, Rigacci S, Coppi E, Pugliese AM, Pantano D, la Marca G, Ed Dami T, Berti A, Stefani M, Casamenti F (2015) Oleuropein aglycone protects against pyroglutamylated-3 amyloid- $\beta$ toxicity: Biochemical, epigenetic and functional correlates. Neurobiol Aging 36, 648-663.

[5] Remely M, Lovrecic L, de la Garza AL, Migliore L, Peterlin B, Milagro FI, Martinez AJ, Haslberger AG (2015) Therapeutic perspectives of epigenetically active nutrients. $\mathrm{Br} J$ Pharmacol 172, 2756-2768.

[6] Graff J, Rei D, Guan JS, Wang WY, Seo J, Hennig KM, Nieland TJ, Fass DM, Kao PF, Kahn M, Su SC, Samiei A, Joseph N, Haggarty SJ, Delalle I, Tsai LH (2012) An epigenetic blockade of cognitive functions in the neurodegenerating brain. Nature 483, 222-226.

[7] Adwan L, Zawia NH (2013) Epigenetics: A novel therapeutic approach for the treatment of Alzheimer's disease. Pharmacol Ther 139, 41-50.

[8] Chung S, Yao H, Caito S, Hwang JW, Arunachalam G, Rahman I (2010) Regulation of SIRT1 in cellular functions: Role of polyphenols. Arch Biochem Biophys 501, 79-90.

[9] Zhang T, Berrocal JG, Frizzell KM, Gamble MJ, DuMond ME, Krishnakumar R, Yang T, Sauve AA, Kraus WL (2009) Enzymes in the NAD+ salvage pathway regulate SIRT1 activity at target gene promoters. J Biol Chem $\mathbf{2 8 4}$, 2040820417.

[10] Canto C, Gerhart-Hines Z, Feige JN, Lagouge M, Noriega L, Milne JC, Elliott PJ, Puigserver P, Auwerx J (2009) AMPK regulates energy expenditure by modulating NAD+ metabolism and SIRT1 activity. Nature 458, 1056-1060.

[11] Martire S, Mosca L, d'Erme M (2015) PARP-1 involvement in neurodegeneration: A focus on Alzheimer's and Parkinson's diseases. Mech Ageing Dev 146-148, 53-64.

[12] Chaitanya GV, Steven AJ, Babu PP (2010) PARP-1 cleavage fragments: Signatures of cell-death proteases in neurodegeneration. Cell Commun Signal 8, 31.

[13] Koh DW, Dawson TM, Dawson VL (2005) Poly(ADPribosyl)ation regulation of life and death in the nervous system. Cell Mol Life Sci 62, 760-768.

[14] de Murcia G, Jacobson M, Shall S (1995) Regulation by ADP-ribosylation. Trends Cell Biol 5, 78-81.

[15] Huang Q, Wu YT, Tan HL, Ong CN, Shen HM (2009) A novel function of poly(ADP-ribose) polymerase-1 in modulation of autophagy and necrosis under oxidative stress. Cell Death Differ 16, 264-277.

[16] Swindall AF, Stanley JA, Yang ES (2013) PARP-1: Friend or foe of DNA damage and repair in tumorigenesis? Cancers (Basel) 5, 943-958.

[17] Caito S, Rajendrasozhan S, Cook S, Chung S, Yao H, Friedman AE, Brookes PS, Rahman I (2010) SIRT1 is a redox-sensitive deacetylase that is post-translationally modified by oxidants and carbonyl stress. FASEB $J \mathbf{2 4}$, 3145-3159.

[18] Abeti R, Duchen MR (2012) Activation of PARP by oxidative stress induced by beta-amyloid: Implications for Alzheimer's disease. Neurochem Res 37, 2589-2596.

[19] Love S, Barber R, Wilcock GK (1999) Increased poly(ADPribosyl)ation of nuclear proteins in Alzheimer's disease. Brain 122(Pt 2), 247-253.

[20] Cecchi C, Fiorillo C, Sorbi S, Latorraca S, Nacmias B, Bagnoli S, Nassi P, Liguri G (2002) Oxidative stress and reduced antioxidant defenses in peripheral cells from 
familial Alzheimer's patients. Free Radic Biol Med 33, 1372-1379.

[21] Rajamohan SB, Pillai VB, Gupta M, Sundaresan NR, Birukov KG, Samant S, Hottiger MO, Gupta MP (2009) SIRT1 promotes cell survival under stress by deacetylationdependent deactivation of poly(ADP-ribose) polymerase 1 . Mol Cell Biol 29, 4116-4129.

[22] Rahmani AH, Albutti AS, Aly SM (2014) Therapeutics role of olive fruits/oil in the prevention of diseases via modulation of anti-oxidant, anti-tumour and genetic activity. Int $J$ Clin Exp Med 7, 799-808.

[23] Watroba M, Szukiewicz D (2015) The role of sirtuins in aging and age-related diseases. Adv Med Sci 61, 52-62.

[24] Chishti MA, Yang DS, Janus C, Phinney AL, Horne P, Pearson J, Strome R, Zuker N, Loukides J, French J, Turner S, Lozza G, Grilli M, Kunicki S, Morissette C, Paquette J, Gervais F, Bergeron C, Fraser PE, Carlson GA, George-Hyslop PS, Westaway D (2001) Early-onset amyloid deposition and cognitive deficits in transgenic mice expressing a double mutant form of amyloid precursor protein 695. J Biol Chem 276, 21562-21570.

[25] Konno K, Hirayama C, Yasui H, Nakamura M (1999) Enzymatic activation of oleuropein: A protein crosslinker used as a chemical defense in the privet tree. Proc Natl Acad Sci U S A 96, 9159-9164.

[26] Buonvicino D, Formentini L, Cipriani G, Chiarugi A (2013) Glucose deprivation converts poly(ADP-ribose) polymerase-1 hyperactivation into a transient energyproducing process. J Biol Chem 288, 36530-36537.

[27] Fiorentini A, Rosi MC, Grossi C, Luccarini I, Casamenti F (2010) Lithium improves hippocampal neurogenesis, neuropathology and cognitive functions in APP mutant mice. PLoS One 5, e14382.

[28] Heeres JT, Hergenrother PJ (2007) Poly(ADP-ribose) makes a date with death. Curr Opin Chem Biol 11, 644-653.

[29] Martire S, Fuso A, Rotili D, Tempera I, Giordano C, De ZI, Muzi A, Vernole P, Graziani G, Lococo E, Faraldi M, Maras B, Scarpa S, Mosca L, d'Erme M (2013) PARP-1 modulates amyloid beta peptide-induced neuronal damage. PLoS One 8, e72169.

[30] Kauppinen TM, Swanson RA (2007) The role of poly(ADPribose) polymerase-1 in CNS disease. Neuroscience 145, 1267-1272.

[31] Chaitanya GV, Steven AJ, Babu PP (2010) PARP-1 cleavage fragments: Signatures of cell-death proteases in neurodegeneration. Cell Commun Signal 8, 31.

[32] Rigacci S, Miceli C, Nediani C, Berti A, Cascella R, Pantano D, Nardiello P, Luccarini I, Casamenti F, Stefani M (2015) Oleuropein aglycone induces autophagy via the AMPK/mTOR signalling pathway: A mechanistic insight. Oncotarget 6, 35344-35357.

[33] Fulco M, Sartorelli V (2008) Comparing and contrasting the roles of AMPK and SIRT1 in metabolic tissues. Cell Cycle 7, 3669-3679.

[34] Zhou J, Ng S, Huang Q, Wu YT, Li Z, Yao SQ, Shen HM (2013) AMPK mediates a pro-survival autophagy downstream of PARP-1 activation in response to DNA alkylating agents. FEBS Lett 587, 170-177.

[35] Hassa PO, Covic M, Hasan S, Imhof R, Hottiger MO (2001) The enzymatic and DNA binding activity of PARP-1 are not required for NF-kappa B coactivator function. J Biol Chem 276, 45588-45597.

[36] Chiarugi A, Moskowitz MA (2003) Poly(ADP-ribose) polymerase-1 activity promotes NF-kappaB-driven transcription and microglial activation: Implication for neurodegenerative disorders. J Neurochem 85, 306-317.

[37] Lian H, Yang L, Cole A, Sun L, Chiang AC, Fowler SW, Shim DJ, Rodriguez-Rivera J, Taglialatela G, Jankowsky JL, Lu HC, Zheng H (2015) NFkappaB-activated astroglial release of complement $\mathrm{C} 3$ compromises neuronal morphology and function associated with Alzheimer's disease. Neuron 85, 101-115.

[38] Casamenti F, Grossi C, Rigacci S, Pantano D, Luccarini I, Stefani M (2015) Oleuropein aglycone: A possible drug against degenerative conditions. In vivo evidence of its effectiveness against Alzheimer's disease. J Alzheimers Dis 45, 679-688.

[39] Morrison RS, Kinoshita Y (2000) The role of p53 in neuronal cell death. Cell Death Differ 7, 868-879.

[40] Kruman II, Culmsee C, Chan SL, Kruman Y, Guo Z, Penix L, Mattson MP (2000) Homocysteine elicits a DNA damage response in neurons that promotes apoptosis and hypersensitivity to excitotoxicity. J Neurosci 20, 6920-6926.

[41] Menon V, Povirk L (2014) Involvement of p53 in the repair of DNA double strand breaks: Multifaceted Roles of p53 in homologous recombination repair (HRR) and non-homologous end joining (NHEJ). Subcell Biochem 85, 321-336.

[42] Oda K, Arakawa H, Tanaka T, Matsuda K, Tanikawa C, Mori T, Nishimori H, Tamai K, Tokino T, Nakamura Y, Taya Y (2000) p53AIP1, a potential mediator of p53-dependent apoptosis, and its regulation by Ser-46-phosphorylated $\mathrm{p} 53$. Cell 102, 849-862.

[43] Chen Y, McMillan-Ward E, Kong J, Israels SJ, Gibson SB (2008) Oxidative stress induces autophagic cell death independent of apoptosis in transformed and cancer cells. Cell Death Differ 15, 171-182.

[44] Xu Y, Kim SO, Li Y, Han J (2006) Autophagy contributes to caspase-independent macrophage cell death. J Biol Chem 281, 19179-19187.

[45] Munoz-Gamez JA, Rodriguez-Vargas JM, Quiles-Perez R, Aguilar-Quesada R, Martin-Oliva D, de Murcia G, Menissier dM, Almendros A, Ruiz dA, Oliver FJ (2009) PARP-1 is involved in autophagy induced by DNA damage. Autophagy 5, 61-74.

[46] Chiu LY, Ho FM, Shiah SG, Chang Y, Lin WW (2011) Oxidative stress initiates DNA damager MNNG-induced poly(ADP-ribose)polymerase-1-dependent parthanatos cell death. Biochem Pharmacol 81, 459-470.

[47] Hassa PO, Buerki C, Lombardi C, Imhof R, Hottiger MO (2003) Transcriptional coactivation of nuclear factorkappaB-dependent gene expression by $\mathrm{p} 300$ is regulated by poly(ADP)-ribose polymerase-1. J Biol Chem $\mathbf{2 7 8 , 4 5 1 4 5 -}$ 45153.

[48] Yeung F, Hoberg JE, Ramsey CS, Keller MD, Jones DR, Frye RA, Mayo MW (2004) Modulation of NF-kappaBdependent transcription and cell survival by the SIRT1 deacetylase. EMBO J 23, 2369-2380.

[49] Langley E, Pearson M, Faretta M, Bauer UM, Frye RA, Minucci S, Pelicci PG, Kouzarides T (2002) Human SIR2 deacetylates p53 and antagonizes PML/p53-induced cellular senescence. EMBO J 21, 2383-2396.

[50] Luo JL, Yang Q, Tong WM, Hergenhahn M, Wang ZQ, Hollstein M (2001) Knock-in mice with a chimeric human/murine p53 gene develop normally and show wildtype p53 responses to DNA damaging agents: A new biomedical research tool. Oncogene 20, 320-328. 